\title{
ANALYSIS OF KINETICS OF MULTICOMPONENT, HETEROGENEOUS GRANULAR MIXTURES - LAMINAR AND TURBULENT FLOW APPROACH
}

\author{
Jolanta B. Królczyk ${ }^{*}$ \\ Opole University of Technology, 76 Prószkowska Street, 45-758 Opole, Poland
}

Mixing of granular materials is unquestionably important. Mixing solids is common in industrial applications and frequently represents a critical stage of the processes. The effect of mixing determines the quality of the products. Achieving a gas or liquid mixture ideally homogeneous in terms of composition in the case of dissolving components is not that difficult, while in case of granular materials that usually differ in sizes and densities, obtaining a homogenous mixture is practically impossible. The aim of the paper is to present the kinetics of mixing of a multicomponent, nonhomogeneous granular mixture. For the first time in mixing of granular materials, a reference has been made to the terminology used in kinematics of fluid mixtures to determine the state of the mixture: turbulent or laminar. By means of statistical analysis the mixing process was divided into two stages. The initial phase of the process was called the stage of turbulent changes, due to large differences in the quality of the observed mixtures; the final step of the process was called the stage of laminar, stable changes, where further mixing did not result in a significant improvement in quality. The research was conducted in industrial conditions in a twotonne mixer.

Keywords: mixing, granular materials, kinetics, turbulent stage, laminar stage

\section{INTRODUCTION}

A granular material can be defined as any material composed of many individual solid particles, irrespective of the particle size. The term granular material includes a wide variety of materials from the coarsest colliery rubble to the finest icing sugar. It has been estimated that at least three-quarters of the raw materials are in form of granular solids (Nedderman, 2005).

Mixing of granular material has been defined as a process of dispersing a few components by chaotic, random movement of grains (Boss, 1987). It is a particular unit operation which occurs in a great number of practical applications and in every processing industry (mining, pharmaceuticals, chemical, civil, mechanical, energy, food and agriculture) (Harnby, 2000; Królczyk et al., 2014, Mendez et al., 2010; Ottino and Khakhar, 2001; Radl et al., 2010). The handling of granular materials is of the greater importance especially in the chemical industry and pharmaceutical where final mixtures homogeneity is rigorously needed (Nedderman, 2005; Santomaso et al., 2004). The effect of mixing determines the quality of the products.

Mixing of solids is a complex process, and its course is influenced primarily by characteristics of the components (shape, average dimensions of particles, bulk density, cohesion), the type of the mixing device and process conditions. This is apparent in better mixing of ingredients or their secondary segregation. Frequently, after the maximum state of mixing is achieved, particles with similar 
properties tend to occupy specific places in the bed. This leads to partial - bigger or smaller separation of the components which puts the mixed system in a dynamically stable, balanced state (Grochowicz et al., 2009). The result of mixing is therefore a function of many parameters.

Mixing solids frequently represents a critical stage of the processes (Santomaso et al., 2004). The knowledge base, however, is less developed than that for fluids (Ottino 1990; Ottino and Khakhar, 2000). Achieving a mixture perfectly homogeneous in terms of composition of the gas or the liquid in the case of dissolving components is not that difficult, while in the case of granular components, with particles varying in size and density, obtaining a homogeneous and random mixture is practically impossible (Borowski et al., 2009). The process of mixing granular materials, in contrast to processes involving chemical reactions, requires continuous movement of the mixed system. The mutual movement of the grain is a source of progress of mixing, but also of secondary segregation (Boss, 1987). In fluids, mixing is a process during which the concentration of ingredients in the system is equalised. Fluid elements of different ingredients move with respect to each other, which leads to turbulent or molecular diffusion processes (Ottino and Wiggins, 2004). When mixing is too slow with respect to the rate of chemical reaction, the performance of the ongoing process can be significantly impaired, which can result in a final product of undesirable composition and properties (Malecha and Malecha, 2014). The knowledge of flow and its turbulent or laminar behaviour is crucial for a better understanding of mixing processes, scale-up modelling, geometry improvement, computational modelling, etc. (Kysela et al., 2014; Zakrzewska et al., 2001). Granular materials show both fluid-like and solid-like behaviour. Under weak shear stress they deform plastically; under high shear stress they flow (Pak and Behringer, 1994). While there are also instances of liquid and gas flows that are difficult to study experimentally, many of these have been examined successfully using computational fluid dynamics. Unfortunately, granular flows are as difficult to simulate as they are to observe. Several techniques have been used: methods based on soil mechanics (Novosad, 1964), continuum models based on the flow of dense gases (Haff, 1986), Monte Carlo models (Rosato et al., 1987) and DEM models that simulate the motion of every particle (Cundall and Stack, 1979; Bridgwater, 2010).

The mixing process is a result of many mechanisms like diffusion, convection or shear (BarbosaCánovas et al., 2005; Choldrich 2002; Paul et al., 2004; Santomaso et al., 2004). The behaviour of granular materials may be considered in relation to the objective of their applications into the industry and solving practical problems connected with statics, where the objective is to predict the stress distributions within a granular material with particular emphasis placed on predicting the forces on the walls of the silo in which the materials are stored, kinematics, the study of motion of flowing granular materials, and dynamics in order to predict the discharge rate from silo (Nedderman, 2005). Mc Carthy et al. (2000) claimed that there is no accepted set of universal governing equations describing granular flow. There are many studies on the process of mixing particulate materials mainly in laboratory scale, typically for two or three components (Arratia et al., 2006; Basinskas and Sakai, 2016; Brone and Muzzio, 2000; Mahmood et al., 2016; Lemieux et al., 2007, Seville et al., 2005). There are not many publications presenting the results of experimental studies conducted in industrial conditions. They are mostly connected with quality assessment of products (Chyłek-Purchała et al., 2014; Djuragic et al., 2009). Each branch of industry has its specific needs and dominant issues, i.e. in pharmaceuticals it is quality assurance, whereas in consumer products-understood as anything from foodstuffs to detergentsit is customisation. The objective to industry is to solve the problem and understanding plays a secondary role. 'Thus, an acceptable solution may be arrived at by massive experimentation or by a clever series of statistically designed experiments'(Ottino and Khakhar, 2001).This approach has been successful in many branches such as granulation, compaction, pharmaceutical powders. Specific solutions are rarely extensible and scaling up is difficult (Fan et al., 1990).

The attempts to quantitatively describe the mixing of granular materials did not bring significant results so far. This is due to the complexity of the issue of mixing and the necessity to include complex phenomena occurring in the mixer; a clearly specified movement of the bed as a whole system and 
simultaneous occurrence of random movements of individual grains, the superposition of randomly occurring homogenization and segregation need to be included (Boss and Szatko, 1998).

The purpose of the paper is to present the kinetics of mixing multicomponent, heterogeneous granular materials. The research was conducted in industrial conditions in a two-tonne mixer. For the first time in mixing of granular materials, reference was made to the terminology used in kinematics of fluid mixtures to determine the state of the mixture: turbulent or laminar flow. Mixing was divided into two stages. The initial phase of the process was called the stage of turbulent changes, due to large differences in the quality of the observed mixtures; the final step of the process was called the stage of laminar, stable changes, where further mixing did not result in a significant improvement in quality. Four granular agreements consisting of many components were tested $(8,12$ and 14$)$.

\section{MATERIALS AND METHODS}

The experiment was carried out in an industrial mixer - a vertical mixer with a stationary chamber with a periodically operating worm agitator. The diagram and dimensions of the device are presented in Fig. 1. Multicomponent heterogeneous granular systems (agro components: grains) are mixed in the presented device. Mixtures of different formulas (Table 1) and of different components are homogenised. They are usually mixtures that have from 8 to 15 components of different properties. Selected parameters characterising the mixed components are presented in Table. 2. The mass of mixed blends was $2100 \mathrm{~kg}$ for three mixtures, and $2200 \mathrm{~kg}$ for one mixture.

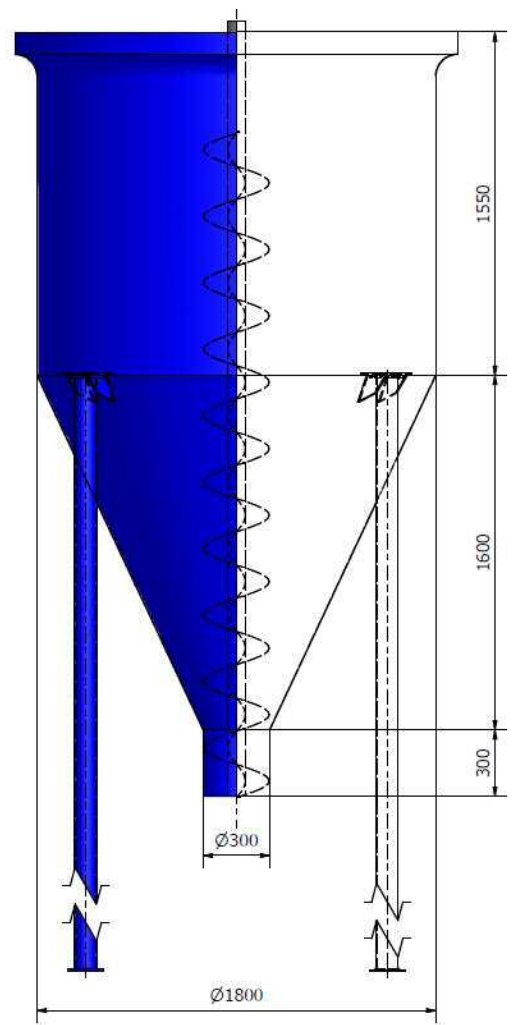

Fig. 1. Scheme of a mixer with worm agitator

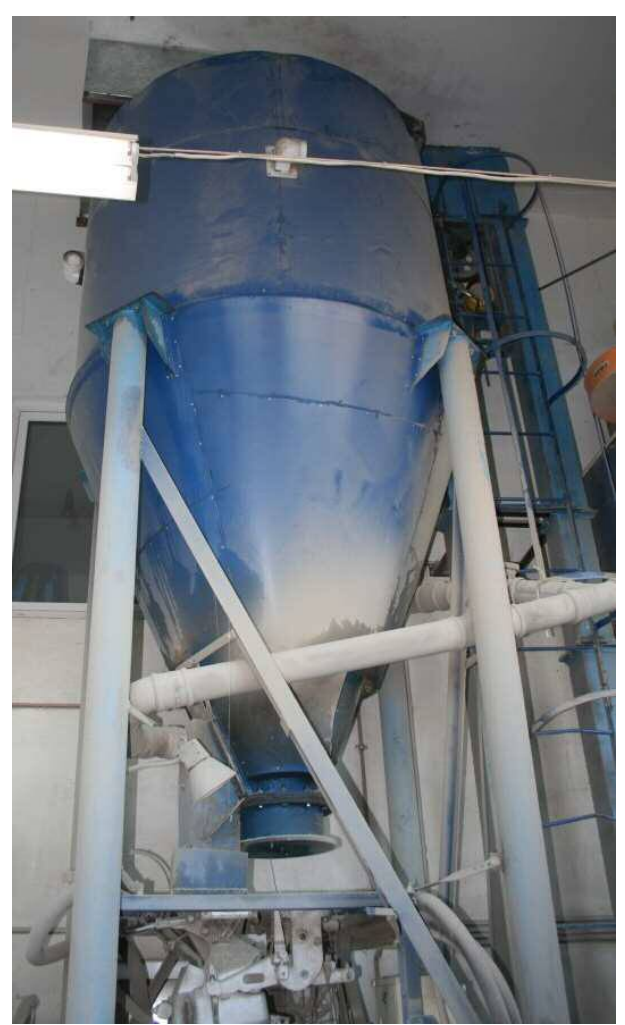

Fig. 2. Mixing line in the following unit: a feed mixer, an intake hopper and a bucket conveyor 
Table 1. Composition of the examined mixtures

\begin{tabular}{|l|c|c|c|c|}
\hline $\begin{array}{c}\text { Number of ingredients of the } \\
\text { mixture }\end{array}$ & 8 & 12 & 12 & 14 \\
\hline Components of the mixture & \multicolumn{4}{|c|}{ Mass shares [kg] } \\
\hline Bright vetch & - & - & 30 & 30 \\
\hline Brown vetch & - & 50 & - & - \\
\hline Carthamus & - & 80 & - & 40 \\
\hline Field pea & - & 170 & 20 & 80 \\
\hline Green pea & 80 & 300 & 80 & 120 \\
\hline Hulled oat & - & 100 & - & 50 \\
\hline Red maize & - & - & 100 & 100 \\
\hline Red millet & - & 25 & 25 & 25 \\
\hline Sorghum & 180 & 320 & 220 & 265 \\
\hline Sunflower & 30 & 90 & 30 & 60 \\
\hline Wheat & 860 & - & 660 & - \\
\hline White rice & - & 50 & - & 25 \\
\hline White sorghum & 20 & 250 & 50 & 150 \\
\hline Yellow maize & 640 & 510 & 700 & 800 \\
\hline Yellow millet & 100 & 155 & 145 & 155 \\
\hline Yellow pea & 190 & - & 140 & 200 \\
\hline & 2100 & 2100 & 2200 & 2100 \\
\hline
\end{tabular}

Table 2. Characteristic properties of mixed granular materials

\begin{tabular}{|l|c|c|}
\hline $\begin{array}{c}\text { Components } \\
\text { of the mixtures }\end{array}$ & $\begin{array}{c}\text { Average size } \\
\text { of particles }[\mathrm{mm}]\end{array}$ & $\begin{array}{c}\text { Bulk density } \\
{\left[\mathrm{kg} \mathrm{m}^{-3}\right]}\end{array}$ \\
\hline Bright vetch & 4.43 & 789 \\
\hline Brown vetch & 4.62 & 799 \\
\hline Carthamus & 4.46 & 499 \\
\hline Field pea & 6.87 & 792 \\
\hline Green pea & 7.22 & 767 \\
\hline Hulled oat & 2.92 & 673 \\
\hline Red maize & 6.65 & 765 \\
\hline Red millet & 2.19 & 721 \\
\hline Sorghum & 3.94 & 697 \\
\hline Sunflower & 4.90 & 430 \\
\hline Wheat & 3.75 & 718 \\
\hline White rice & 2.25 & 758 \\
\hline White sorghum & 3.89 & 687 \\
\hline Yellow maize & 8.17 & 726 \\
\hline Yellow millet & 2.26 & 732 \\
\hline Yellow pea & 6.94 & 771 \\
\hline
\end{tabular}


The experimental material is one of the most frequently mixed types of fodder (foodstuff for pigeons) in the fodder mixing plant. The component proportions (recipe) meet the specific needs of birds (for moulting, breeding, flights) or the customers' requirements (such as 'without wheat' - the customer may add his or her own wheat). The feed should be complete, balanced and contain all the nutrients necessary for proper development of the animals. The purpose of mixing is to ensure appropriate share of individual components in each dosed portion. The process was characterised by the recirculation of the components performed by the bucket elevator. The poured granular material was emptied in the place of discharge, and then directed to the bucket elevator from which it went back to the mixer (Fig. 3). Thus, the mixing took place owing to the movements of the mixing screw and the recirculation through the bucket elevator.

The reason of recirculating the mixture was to clean the feed from small impurities (husks, shells, dust). In the industry practice the mixing cycle including recirculation lasted 30 minutes, but for the experiment purposes of analysing the kinetics of the mixing process and for cognitive purposes, the mixing process was extended to 50 minutes. The samples to be examined were taken during the process of mixing with recirculation every 30 seconds at the discharge end of the mixer (100 samples in every experiment). The experiment was carried out for four different granular mixtures. The mass fractions of the research samples were converted into percentage fractions.

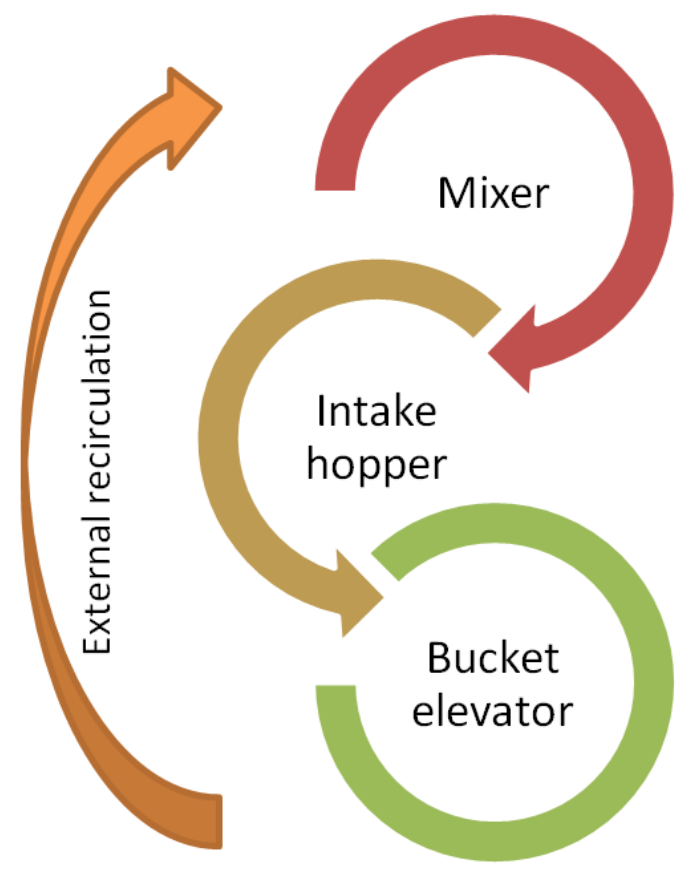

Fig. 3. Schematic diagram of mixing

\section{STATISTICAL ASSESSMENT}

Statistical analysis was carried out in several stages. The diagram of analysis and the analysis of results was shown in Fig. 4.

The output data matrix is the percent portion of each of the component (Table 2) depending on the time of mixing. An important parameter of the mixing process is the time required to achieve the assumed state of the mixture. Analysis of percentage changes of the components' share in the mixture inclined to searching for a parameter, which would determine the mixture's quality in a certain unit of time with only one universal numerical value. The residual sum of squares was used as a parameter for description of the mixture's quality. 
Due to the fact that the research samples was taken in a different way than conventionally (sampling from the interior of the mixer at a different height of the bed), the classic, described in the literature, description of the quality measures cannot be applied to describe the mixing process. The analysis of changes in percentage shares of components in mixtures stimulates the search parameter, which would define with a single numerical value the quality of the mixture in a given period of time. For this purpose a parameter of linear regression - residual sum of squares was used (SSE - error sum of squares or residual sum of squares) (Aczel, 2005).

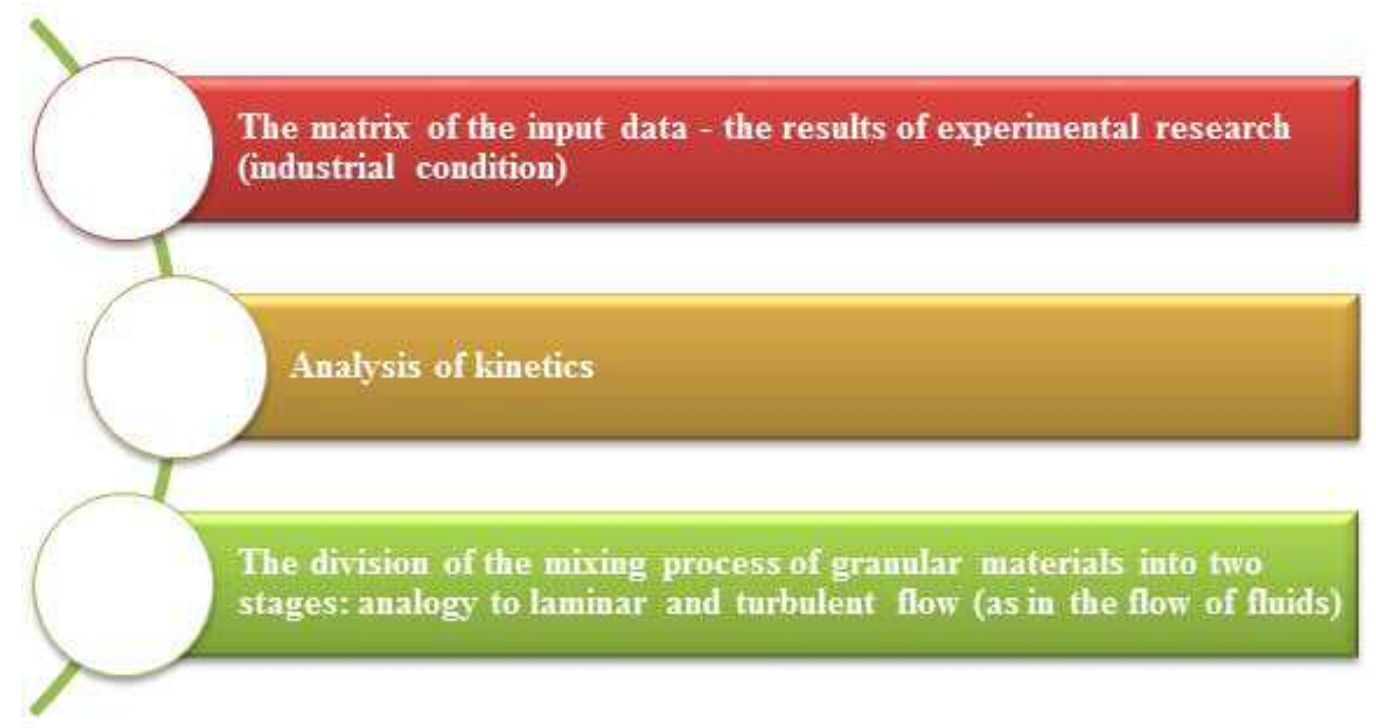

Fig. 4. Diagram of statistical analysis

Relationships between two variables were modelled:

- dependent variable $\mathrm{Y}$ - target frequency distribution of components,

- independent variable $\mathrm{X}$ - distributions shares of particular components in the following intervals.

Simple regression model (for the population) consists of a random component (a straight line) designated by the element $\beta_{0}+\beta_{1} X$ in Eq. (1) and a random component $\varepsilon$ (random error):

$$
Y=\beta_{0}+\beta_{1} X+\varepsilon
$$

Estimation of the above regression equation is the following equation:

$$
Y=b_{0}+b_{1} X+e
$$

The study analyses the errors observed by matching a regression model to the data by the least squares method. The observed errors inform to what extent the results of observation are not explained by the model (Aczel, 2005).

The residual sum of squares is defined as follows:

$$
R S S=\sum_{i=1}^{n} e_{i}^{2}=\sum_{i=1}^{n}\left(y_{i}-\hat{y}_{i}\right)^{2}
$$

The residual sum of squares is a sum of squares of differences between values of the $Y$ variable (target frequency distribution of components) and evaluations obtained from simple regression. When the RSS parameter achieves the value of zero, then shares of all components in a specific time point will be equal to target values, consequently, the best quality of mixture is achieved. However, in practice it is very difficult to achieve RSS close to zero, especially when we deal with multi-ingredient compositions. The qualities of granular mixtures were described this way in the authors' previous 
articles (Królczyk, 2014). Results of mixing are shown in Figs. 5 - 8. In a further step of a statistical analysis the process was divided into two stages (all possible divisions of the process into two steps were included). The Mann-Whitney $U$ was applied for this purpose. The amplitude of deviations from the maximum values (local maxima of the function) was determined for all RSS changes in time (kinetics of mixing). Next, the amplitudes were matched with the corresponding minutes of the mixing process and a test was performed in order to divide the process into two stages.

The statistical significance of the test for two groups of designated minutes - for turbulent and gentle mixing - was checked. A visual assessment of the course of laminar and turbulent changes presented on charts allowed an arbitrary assumption of each minute of the process belonging to the selected group. This fact, however, required statistical proof. Therefore, the test was performed. In the following steps the significance of the test for different cases of the division process was checked. To divide the process into two stages, a minimum value of the statistical test was selected.

\section{RESULTS AND DISCUSSION}

The results are presented in Table 3 . This is the input data for the statistical analysis.

Table 3. Percentage share of one of the examined mixtures (14 ingredients) depending on the mixing time

\begin{tabular}{|l|c|c|c|c|c|c|c|c|c|c|}
\hline \multirow{2}{*}{$\begin{array}{l}\text { Components } \\
\text { of the mixture }\end{array}$} & \multirow{2}{*}{$\begin{array}{c}\text { Required } \\
\text { share }\end{array}$} & \multicolumn{7}{|c|}{ Percentage share during mixing time [s] } \\
\cline { 3 - 12 } & 30 & 60 & 90 & 120 & $\ldots$ & 2910 & 2940 & 2970 & 3000 \\
\hline Bright vetch & 1.43 & 0.0000 & 0.0000 & 0.0000 & 0.0000 & $\ldots$ & 0.0056 & 0.0043 & 0.0047 & 0.0069 \\
\hline Carthamus & 1.90 & 0.0008 & 0.0000 & 0.0080 & 0.0492 & $\ldots$ & 0.0197 & 0.0205 & 0.0173 & 0.0223 \\
\hline Field pea & 3.81 & 0.0662 & 0.0232 & 0.0216 & 0.0033 & $\ldots$ & 0.0361 & 0.0626 & 0.0356 & 0.0472 \\
\hline Green pea & 5.71 & 0.1355 & 0.0075 & 0.0000 & 0.0000 & $\ldots$ & 0.0526 & 0.0619 & 0.0623 & 0.0412 \\
\hline$\ldots$ & $\ldots$ & $\ldots$ & $\ldots$ & $\ldots$ & $\ldots$ & $\ldots$ & $\ldots$ & $\ldots$ & $\ldots$ & $\ldots$ \\
\hline White rice & 1.19 & 0.0003 & 0.0000 & 0.0000 & 0.0000 & $\ldots$ & 0.0056 & 0.0043 & 0.0047 & 0.0069 \\
\hline $\begin{array}{l}\text { White } \\
\text { sorghum }\end{array}$ & 7.14 & 0.0030 & 0.0001 & 0.0004 & 0.2609 & $\ldots$ & 0.0456 & 0.0361 & 0.0397 & 0.0528 \\
\hline Yellow maize & 38.10 & 0.2591 & 0.8678 & 0.1343 & 0.0016 & $\ldots$ & 0.5074 & 0.4796 & 0.4848 & 0.4850 \\
\hline Yellow pea & 9.52 & 0.4456 & 0.0095 & 0.0059 & 0.0034 & $\ldots$ & 0.1031 & 0.1382 & 0.1461 & 0.1289 \\
\hline
\end{tabular}

The average mass was for: 8 ingredient mixture - $154.53 \mathrm{~g}$ (standard deviation 10.86); 12 ingredient mixture (with brown vetch) - 161.17 (standard deviation 11.92), 12 ingredient mixture (with bright vetch) - 172.38 (standard deviation 25.66), 14 ingredient mixture $178.77 \mathrm{~g}$ (standard deviation 13.94). The samples were separated manually into individual components.

The obtained values of the residual sum of squares for the examined 8, 12 and 14 component mixtures are presented graphically in Figs. $5-8$.

The graphs (Figs. 5 - 8) clearly show greater variability (greater range of scattering) of RSS parameter at the beginning of the mixing process. The RSS value is initially 0.16 for the 8 -component mixture, $0.055,0.13$ for the 12-component mixture, and 0.12 for the 14-component mixtures. With time, the quality of granular mixture improves, approaching the value of 0 , that is of ideal mixture in which the mixture required by the formula is achieved and is uniform throughout. After reaching a certain point in the process of mixing (different types for different mixtures), a clear improvement in the quality of 
granular mixtures cannot be seen. This observation led the author of the paper to the conclusion that shortening the mixing time is, to improve the economic efficiency of the mixing process. Furthermore, previous experimental studies conducted by the author for 30-minute-long mixing of other granular mixtures have shown that in these mixtures, there are two clearly distinguishable states of the mixture (Królczyk, 2012). The process was divided into two stages: the stage of turbulent changes and the stage of gentle, or laminar changes, by analogy with the laminar (orderly, stable) and turbulent flow in fluids. In order to determine the boundary between the turbulent and laminar mixing process the MannWhitney U was used. Amplitudes plotted to a graph of RSS changes over time are shown in Fig. 9. The results of the division of the mixing process into two stages: the turbulent and the laminar changes for the mixtures, were shown in Figs. 9 - 12.

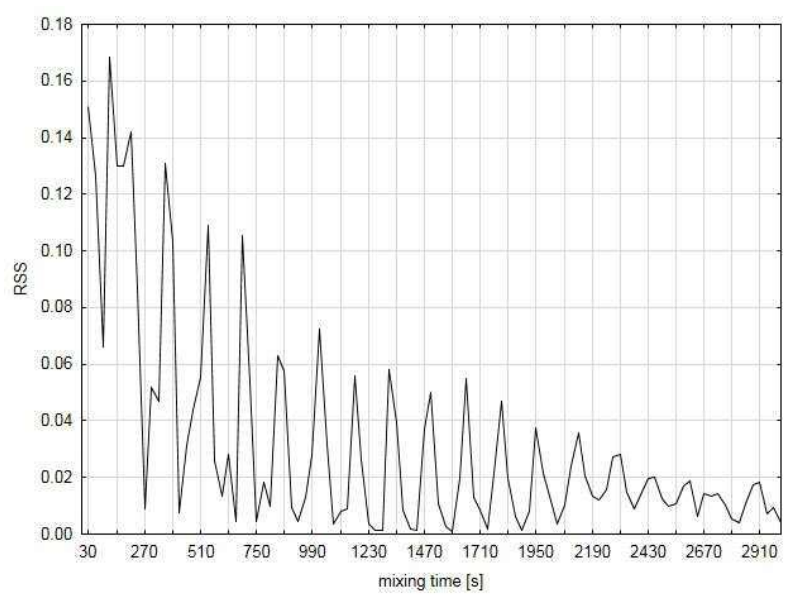

Fig. 5. Kinetics of 8-component granular mixture

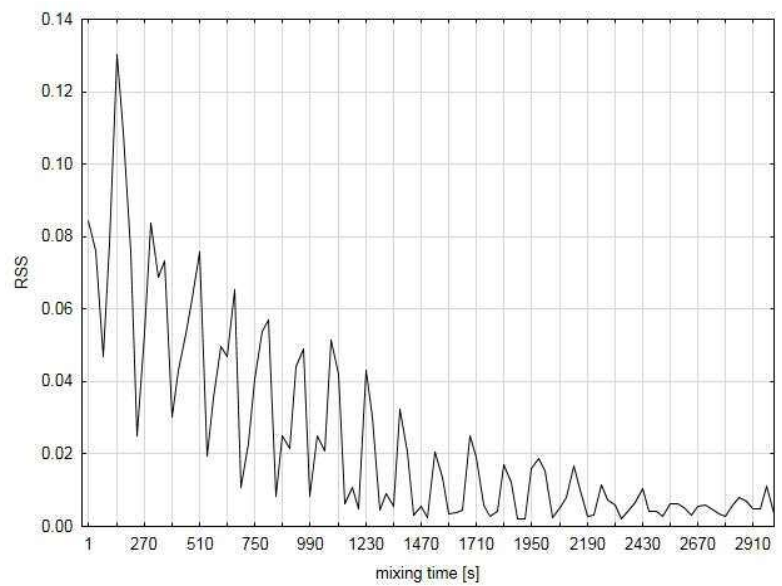

Fig. 7. Kinetics of the second 12-component granular mixture

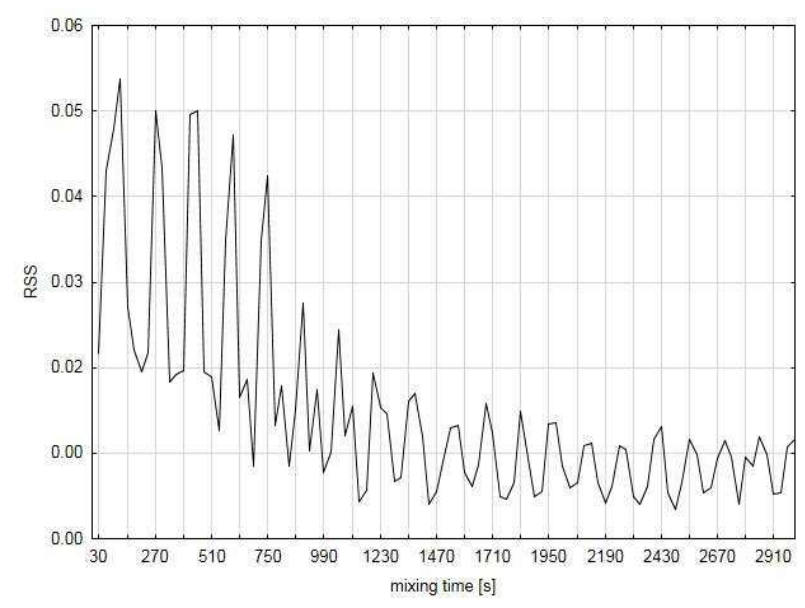

Fig. 6. Kinetics of 12-component granular mixture

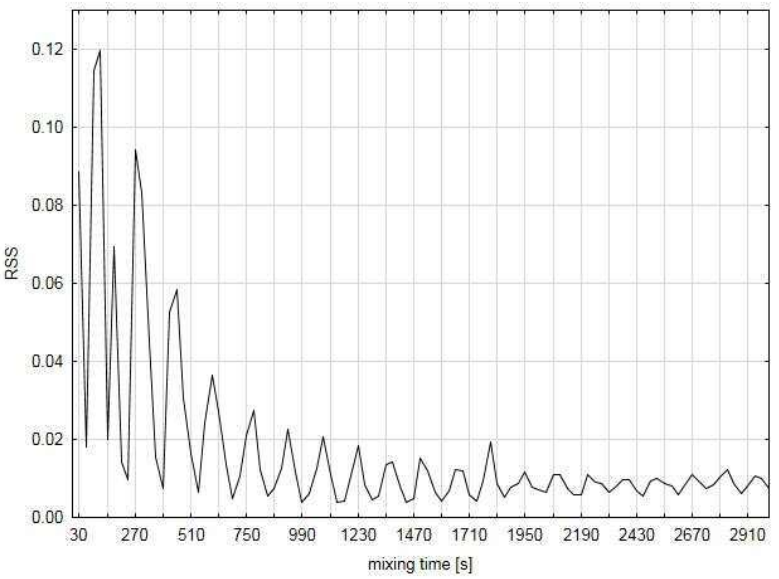

Fig. 8. Kinetics of 14-component granular mixture

The red line on the graphs marks the area of turbulent changes of the biggest changes in the quality of granular mixtures, while the green line indicates the area of small changes in quality, also known as laminar. The boundary between the two areas was determined by the Mann-Whitney U test. To divide the process, the minimum value of test significance - ' $p$ ' - was assumed; it was obtained for various possibilities of dividing the process into two stages. For 8-component granular mixture, the minimum value of ' $p$ ' was 0.002516 . It divided the process into two steps consisting of 14 amplitudes at the turbulent changes stage, and therefore to 1800 seconds of mixing (30 minutes) (Fig. 9). The remaining 
20 minutes of the process was the laminar (stable) changes stage, where no significant changes in the quality of the mixture were observed. In the next graph, granular mixture consisting of 12 components (with brown vetch) the minimum value of the ' $p$ ' test was 0.000050 and divided the process in the following way: the turbulent changes stage lasted until the 1380th second of the process; therefore, the first period lasted 23 minutes, while the period of laminar changes took the remaining 27 minutes (Fig. 10). For the second mixture consisting also of 12 components (with fair vetch), the period of turbulent changes lasted until the 18th minute (1080 seconds), while the remaining duration of the mixing process is the period of laminar changes (Fig. 11).

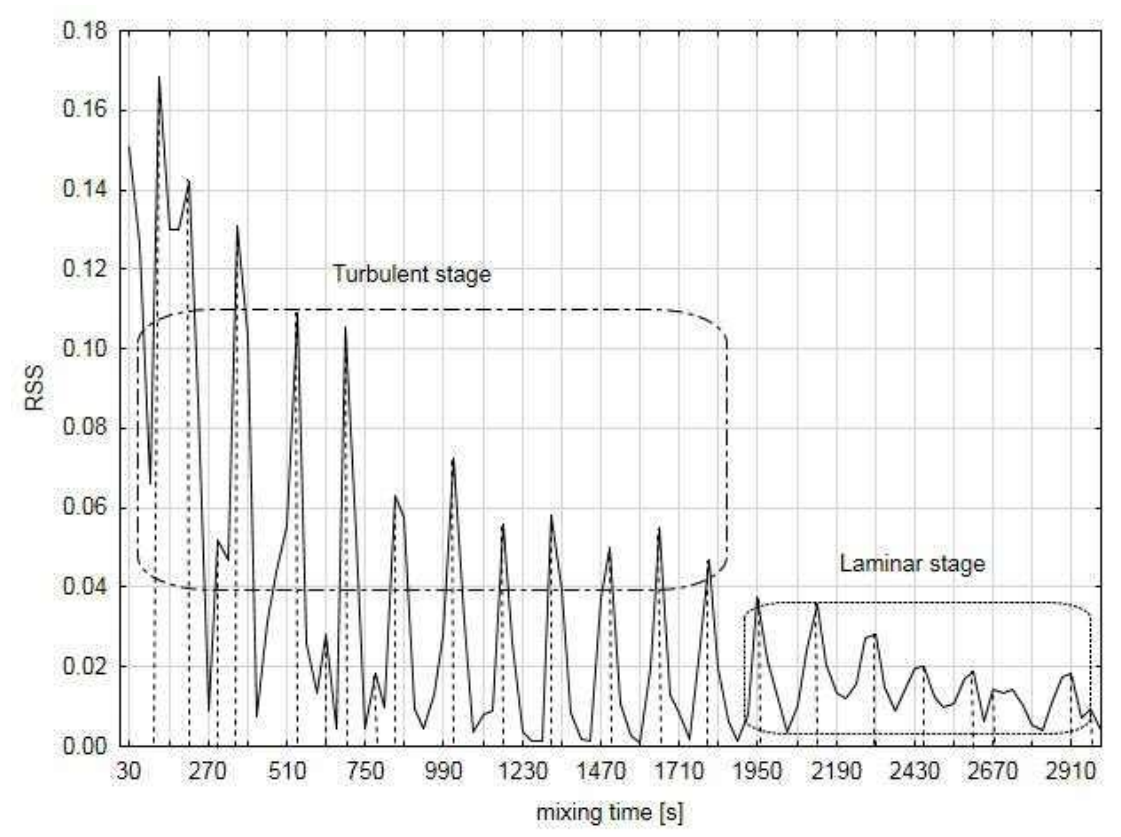

Fig. 9. The division of the process into two stages: turbulent and laminar for 8-component granular mixture with the amplitudes of deviations from the target value

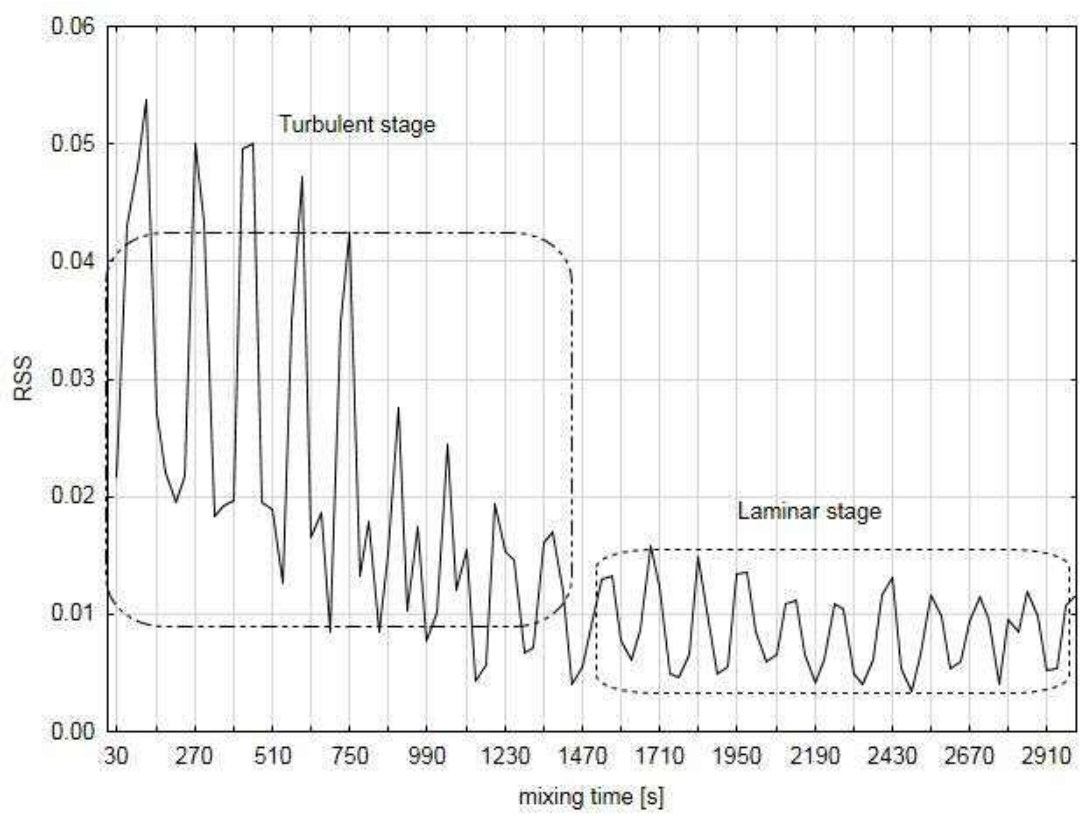

Fig. 10. The division of the process into two stages: turbulent and laminar for a 12-component granular mixture (with brown vetch) 


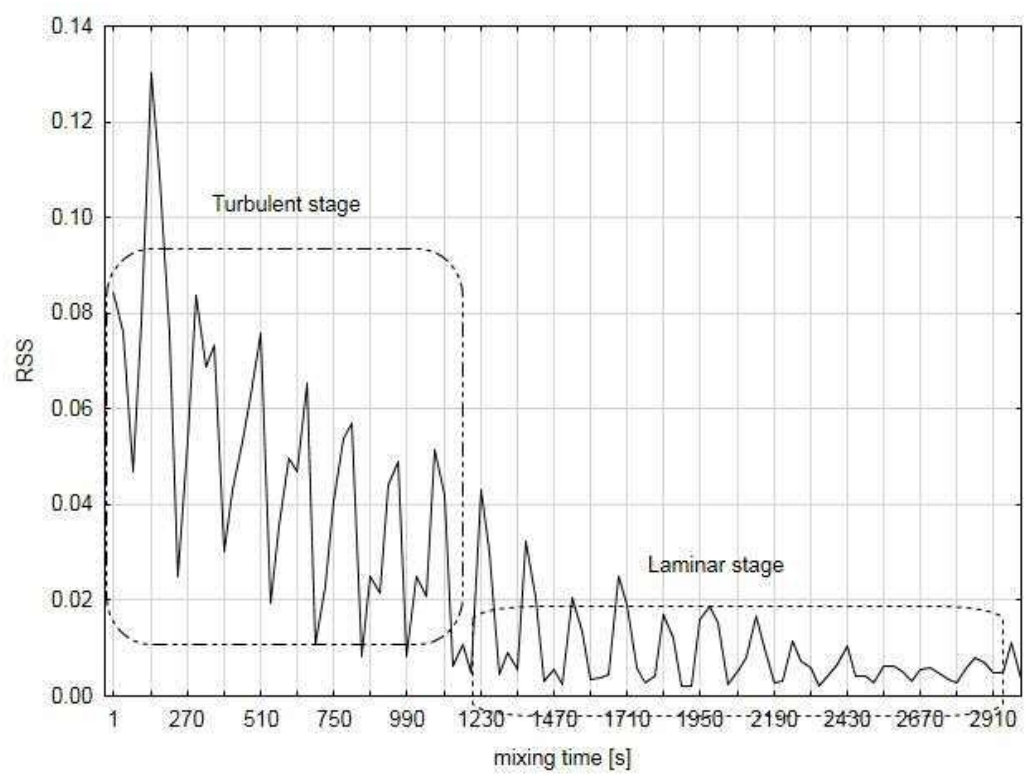

Fig. 11. The division of the process into two stages: turbulent and laminar for a 12-component granular mixture (with fair vetch)

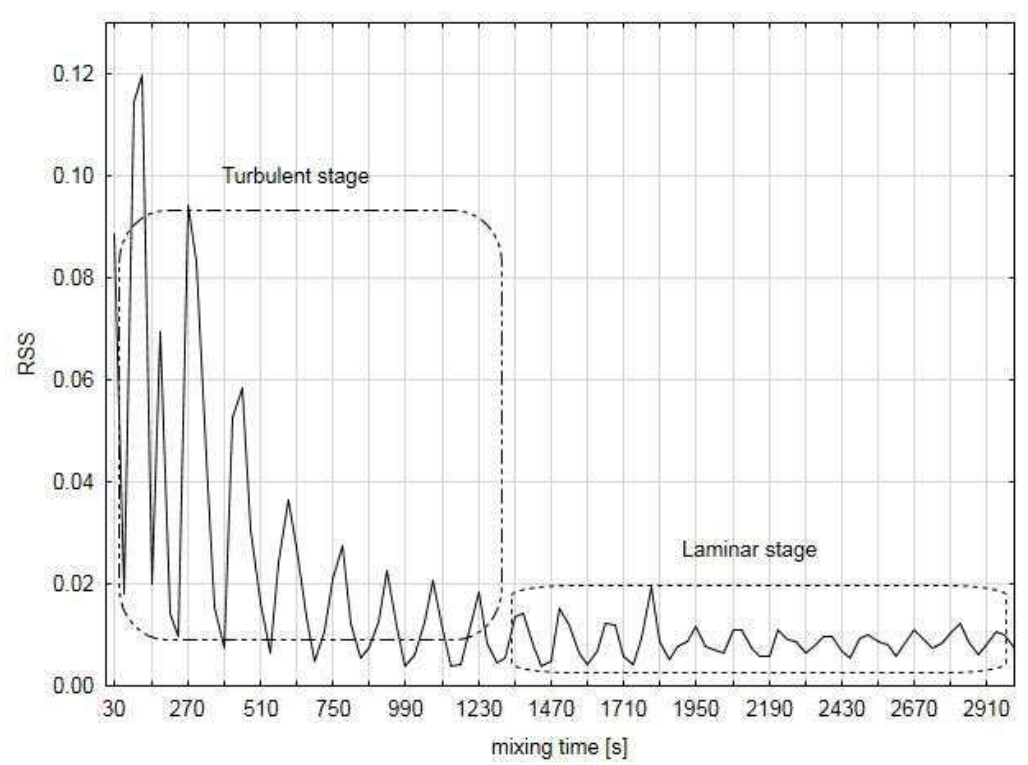

Fig. 12. The division of the process into two stages: turbulent and laminar for a 14-component granular mixture

For the 14-component granular mixture, the period of turbulent changes lasted 20.5 minutes (1230 seconds), and the period of laminar changes lasted the remaining time - almost 30 minutes (Fig. 12). To summarise, the duration of turbulent changes ranged from 18 to 30 minutes, but the laminar period lasted from 20 to 32 minutes. On this basis, it can be concluded that it is advisable to shorten the mixing time in all experiments by the period of stable changes.

\section{CONCLUSIONS}

Analysis of the kinetics of multicomponent, heterogeneous granular mixtures enables their the division into two phases (states): the phase of turbulent changes and the laminar phase. For the first time, terminology was proposed for mixing granular materials that had so far been used for flows in fluid kinematics - turbulence and laminar flow. In the first minutes of the mixing process, significant 
differences were observed. The amplitude of the RSS parameter changes was significantly higher than that for the second stage of laminar changes, where the quality of the mixtures also varied, but to a smaller degree.

Using statistical analysis (statistical test Mann-Whitney U) the process was divided into two stages. The length of the individual stages of mixing was different for different mixtures. The range of turbulent changes ranged from 18 to 30 minutes of mixing, while the laminar changes period lasted from 20 to 32 minutes. For the 8-component mixture, the first stage lasted 30 minutes, while the laminar changes lasted for 20 minutes. For a mixture of 12 components (the brown vetch), the first stage was 23 minutes long and the laminar changes lasted the remaining 27 minutes. For the second mixture, composed also of 12 components (with fair vetch), the period of turbulent changes was the shortest, up to 18 minutes. For the 14-component granular mixtures the period of turbulent changes lasted 20.5 minutes. The quality of granular mixtures described by RSS varied throughout the 50 minutes of mixing, aiming to achieve the value of 0 , and thus to achieve a state of perfect mixture, consistent with the formula and desired by the manufacturer, which in industrial practice is impossible to achieve, especially for systems that significantly differ in density and average diameters, as was the case in the analysed experiment. For each of the tested granular mixtures, it is not necessary for the mixing process to be so long, because after some time (of the turbulent change stage), the process is stabilised and further mixing does not improve the quality of the compound, so the mixing process can be shortened by a period of laminar (stable) changes. This solution will improve the economics of the process, such as lower power consumption and reduced exploitation caused by the operation of the mixer and its moving parts.

\section{SYMBOLS}

$\begin{array}{ll}b_{0} & \text { estimation } \beta_{0} \\ b_{1} & \text { estimation } \beta_{l} \\ e & \text { observed errors (residues) from matching a straight line } b_{0}+b_{1} X \text { to a set of } n \text { observations } \\ R S S & \text { the residual sum of squares } \\ e_{i} & \text { error } i \text { - observation } \\ X & \text { independent variable } \\ y_{i} & \text { target frequency distribution of component (components share }- \text { recipe) } \\ \hat{y}_{i} & \text { value } y \text { predicted from evaluation obtained from simple regression } \\ Y & \text { dependent variable }\end{array}$

Greek symbols

$\beta_{0} \quad$ model parameter, intercept

$\beta_{l} \quad$ model parameter, slope coefficient

$\varepsilon \quad$ random error

\section{REFERENCES}

Aczel A.D., 2005. Complete business statistics. PWN, Warszawa (in Polish).

Arratia P.E., Duong N.H., Muzzio F.J., Godpole P., Lange A., Reynolds S., 2006. Characterizing mixing and lubrication in the Bohle bin blender. Powder Technol., 161, 202-208. DOI: 10.1016/j.powtec.2005.10.009.

Barbosa-Cánovas G.V., Ortega-Rivas E., Juliano P., Yan H., 2005. Food powders physical properties. Processing and functionality. Springer-Verlag, New York.

Basinskas G., Sakai M., 2016. Numerical study of the mixing efficiency of a ribbon mixer using the discrete element method. Powder Technol., 287, 380-394. DOI: 10.1016/j.powtec.2015.10.017. 
Borowski J., Broniarz-Press L., Narożny G., 2009. Porównanie efektywności mieszania materiałów ziarnistych w mieszalnikach mechanicznych i statycznych. Inż. Ap. Chem., 48, 1, 84-85.

Boss J., 1987. Solid mixing process. PWN, Warszawa - Wrocław (in Polish).

Boss J., Szatko W., 1998. Kinetyka mieszania materiałów ziarnistych. Model reakcji następczych. Inż. Chem. Proces.. 19, 3, 591-604.

Bridgwater J., 2010. Mixing of particles and powders: Where next? Particuology, 8, 563-567. DOI: 10.1016/j.partic.2010.07.001.

Brone D., Muzzio F.J., 2000. Enhanced mixing in double-cone blenders. Powder Technology, 110, $179-189$. DOI:10.1016/S0032-5910(99)00204-1.

Choldrich R., 2002. Fundamentals of particle technology. Midland Information Technology and Publishing, Loughborough.

Chyłek-Purchała M., Kozak B., Siwczyńska M.P., Grelik A., Kwiatek K., 2014. Determination of active substances and homogeneity of medicated feeds - Results for 2006 - 2013. Pasze Przemysłowe, 3, 71-76 (in Polish).

Cundall P.A., Stack O. D.L., 1979. A discrete numerical model for granular assemblies. Géotechnique, 29, 47-65. DOI: 10.1680/geot.1979.29.1.47.

Djuragic O., Levic J., Sredanovic S., Levic L., 2009. Evaluation of homogeneity in feed by method of microtracers ${ }^{\circledR}$. Archiva Zootechnica, 12.

Fan L.T., Chen Y.-M., Lai F.S., 1990. Recent developments in solids mixing. Powder Technol., 61, $255-287$. DOI: 10.1016/0032-5910(90)80092-D.

Grochowicz J., Zawiślak K., Sobczak P., 2009. Ocena skuteczności mieszania materiałów ziarnistych z zastosowaniem jako wskaźnika grochu. Inż. Ap. Chem., 48, 1, 96-97.

Haff P.K., 1986. A physical picture of kinetic granular fluids. J. Rheology, 30, 931-948. DOI: 10.1122/1.549875.

Harnby N., 2000. An engineering view of pharmaceutical powder mixing. Pharm. Sci. Technol. Today, 3. 303309. DOI: $10.1016 /$ S1461-5347(00)00283-2.

Królczyk J., 2012. Mixing process of multicomponent granular mixtures in a screw mixer. Zastosowanie metod statystycznych w badaniach naukowych IV, Kraków, StatSoft Polska, Kraków 2012, 295-304 (in Polish).

Królczyk J.B., 2014. An attempt to predict quality changes in a ten-component granular system. Tehnicki VjesnikTechnical Gazette, 21 (2), 255-261.

Królczyk J.B., Rezwiakow A., Tukiendorf M., 2014. Mixing of biomass and coal in a static mixer as an example of technological solutions involving implementation of renewable energy sources. Ecol. Chem. Eng. S, 21, 685696. DOI: 10.1515/eces-2014-0050.

Kysela B., Konfršt J., Fořt I., Kotek M., Chára Z., 2014. Study of the turbulent flow structure around a standard rushton impeller. Chem. Process Eng., 35, 137-147. DOI: 10.2478/cpe-2014-0010.

Lemieux M., Bertrand F., Chaouki J., Gosselin P., 2007. Comparative study of the mixing of free-flowing particles in a V-blender and a bin-blender. Chem. Eng. Sci., 62, 1783-1802. DOI: 10.1016/j.ces.2006.12.012.

Mahmood S., Hilmi N.N.B., Husain N.K.B., Chatterjee B., Mandal U.K., 2016. Differential scanning calorimetric characterization of pharmaceutical powder blend uniformity in a laboratory-scale V-blender. Powder Technol., 287, 152-159. DOI: 10.1016/j.powtec.2015.10.004.

Malecha Z.M., Malecha K., 2014. Numerical analysis of mixing under low and high frequency pulsations at serpentine micromixers. Chem. Process Eng., 35, 369-385. DOI: 10.2478/cpe-2014-0028.

McCarthy J.J., Khakhar D.V., Ottino J.M., 2000. Computational studies of granular mixing. Powder Technol., 109, 72-82. DOI: 10.1016/S0032-5910(99)00228-4.

Mendez A.S., de Carli G., Garcia C.V., 2010. Evaluation of powder mixing operation during batch production: Application to operational qualification procedure in the pharmaceutical industry. Powder Technol., 198, 310313. DOI: 10.1016/j.powtec.2009.11.027.

Nedderman R.M., 2005. Statics and kinematics of granular materials. Cambridge University Press.

Novosad J., 1964. Studies on granular materials. I. Kinematics of granular materials mixed by a mechanical impeller. Collect. Czech. Chem. Commun., 29, 2681-2696.

Ottino J.M., 1990. Mixing, chaotic advection, and turbulence. Annu. Rev. Fluid Mech., 22, 207-54. DOI: 10.1146/annurev.fl.22.010190.001231.

Ottino J.M., Khakhar D.V., 2000. Mixing and segregation of granular materials. Annu. Rev. Fluid Mech., 32, 5591. DOI: 10.1146/annurev.fluid.32.1.55. 
Ottino J.M., Khakhar D.V., 2001. Fundamental research in heaping, mixing, and segregation of granular materials: Challenges and perspectives. Powder Technol., 121, 117-122. DOI: 10.1016/S0032-5910(01)00361-8.

Ottino J.M., Wiggins S., 2004. Introduction: Mixing in microfluidics. Philos. Trans. R. Soc. London, Ser. A, 362, 923-935. DOI: 10.1098/rsta.2003.1355.

Pak H.K., Behringer P.R., 1994. Bubbling in vertically vibrated granular materials. Nature, 371, 231 - 233. DOI: $10.1038 / 371231 \mathrm{a} 0$.

Paul E.L., Atiemo-Obeng V.A., Kresta S.M. (Eds.), 2004. Handbook of industrial mixing: Science and practice. John Wiley \& Sons.

Radl S., Kalvoda E., Glasser B.J., Khinast J.G., 2010. Mixing characteristics of wet granular matter in a bladed mixer. Powder Technol., 200, 171-189. DOI: 10.1016/j.powtec.2010.02.022.

Rosato A., Strandburg K.J., Prinz F., Swendsen R.H., 1987. Why the Brazil nuts are on top: Size segregation of particulate matter by shaking. Phys. Rev. Lett., 58, 1038-1040. DOI: 10.1103/PhysRevLett.58.1038.

Santomaso A., Olivi M., Canu P., 2004. Mechanisms of mixing of granular materials in drum mixers under rolling regime. Chem. Eng. Sci., 59, 3269-3280. DOI: 10.1016/j.ces.2004.04.026.

Seville J.P.K., Ingram A., Parker D. J., 2005. Probing processes using positrons. Chem. Eng. Res. Des., 83, 788793. DOI: $10.1205 /$ cherd.04323.

Zakrzewska B., Peryt S., Jaworski Z., 2001. Badania przyściennego przepływu przejściowego i burzliwego w mieszalniku cieczy. I. Pomiary anemometryczne. Inż. Chem. Proces., 22, 427-443.

Received 30 April 2015

Received in revised form 02 September 2015

Accepted 18 February 2016 